\title{
ESTRUTURA E DESENVOLVIMENTO DE CANAIS SECRETORES EM FRUTOS DE SCHINUS TEREBINTHIFOLIUS RADDI (ANACARDIACEAE)
}

\author{
Silvia Rodrigues Machado ${ }^{1}$ \\ Sandra Maria Carmello-Guerreiro ${ }^{2}$
}

Recebido em 12/07/00. Aceito em 23/03/01

\begin{abstract}
RESUMO - (Estrutura e desenvolvimento de cavidades secretoras em frutos de Schinus terebinthifolius Raddi (Anacardiaceae)). As cavidades secretoras no fruto de Schinus terebinthifolius foram analisadas aos microscópios de luz e eletrônico de transmissão. Estas cavidades são complexas e constituídas por epitélio multiestratificado que circunda o lume preenchido por secreção viscosa e por células epiteliais isoladas. Cada cavidade é circundada externamente por duas ou três camadas de células menores que as adjacentes achatadas, radialmente e que progressivamente diferenciam-se em epiteliais. As cavidades secretoras iniciam-se por esquizogênese e desenvolvem-se pelo processo esquizo-lisígeno. O lume inicia-se pela dissolução da lamela média entre um grupo de células precursoras dispostas em roseta; sua ampliação é decorrente da separação das células internas desta roseta. As células epiteliais jovens possuem citoplasma denso com mitocôndrias conspícuas, retículo endoplasmático rugoso extensivo, numerosos corpos multivesiculares e plastídeos modificados. Grumos de material eletron-denso, destituídos de membrana, ocorrem no citoplasma periférico, espaço periplasmático, bem como dispersos no lume da cavidade. À medida que a diferenciação progride, as células epiteliais mais internas são continuamente liberadas para o lume, onde sofrem degeneração. A lisogênese destas células acrescenta materiais à secreção e permite, também, o alargamento da cavidade. As evidências deste trabalho indicam que a secreção nos frutos de $S$. terebinthifoliusé eliminada pelos mecanismos écrino e holócrino.
\end{abstract}

Palavras-chave - cavidades secretoras, anatomia, ultra-estrutura, frutos, Anacardiaceae

\begin{abstract}
Structure and development of the secretory cavities in the fruit of Schinus terebinthifolius Raddi (Anacardiaceae)). The secreory cavities in fruits of Schinus terebinthifolius Raddi were studied by optical and electron microscopy. These are complex cavities with a multistratified epithelium, surrounding a lumen filled with whole cells and viscous fluid. Each cavity is surrounded by two or three layers, radially flattened cells, which will progressively mature into epithelial cells. The secretory cavities initiate schizogenously and develop schizolysigenously. The lumen appears by the dissolution of the middle lamela in a group of precursor cells arranged in a rosette, and widens by the separation of the inner cells of this rosette. The young epithelial cells have dense cytoplasm with large mitochondria, extensive rough endoplasmic reticulum, numerous multivesicular bodies, and modified plastids. Clumps of electrondense material without a delimiting membrane occur the peripheral cytoplasm, periplasmic space, and scattered in the cavity lumen. As differentiation progresses, the innermost epithelial cells are continuously released into the lumen and degenerate. Lysigeny of these cells contributes with materials to secretion, also leading to cavity enlargement. Optical and ultastructural data indicate that secretion elimination occurs by ecrine and holocrine mechanisms.
\end{abstract}

Key words - secretory cavities, anatomy, ultrastructure, fruits, Anacardiaceae

\footnotetext{
${ }^{1}$ Departamento de Botânica, Instituto de Biociências, UNESP, C. Postal 510, CEP 18618-000, Botucatu, SP, Brasil, (botanica@ibb.unesp.br). Bolsista de Produtividade em Pesquisa, CNPq

2 Departamento de Botânica, Instituto de Biologia, UNICAMP, Caixa Postal 6109, CEP 13083-970, Campinas, SP, Brasil (smcg@unicamp.br)
} 


\section{Introdução}

Uma das características da família Anacardiaceae é a presença de canais/cavidades de goma-resina, geralmente associados ao floema (Metcalfe \& Chalk 1950). Nos frutos, o sistema secretor, bastante desenvolvido e representado por canais ou cavidades, ocupa quase todo o mesocarpo (CarmelloGuerreiro 1996), o que levou Barroso et al. (1984) a denominá-lo mesocarpo lacunar.

Schinus terebinthifolius Raddi, uma espécie arbórea comum na América do Sul e conhecida como pimenta-rosa ou aroeira-vermelha (Carmello-Guerreiro \& Paoli 1999), é uma importante fonte de goma-resina da família Anacardiaceae. Seu exudato tem propriedades febrífuga, homeostática e antitussígena (Oliveira \& Grotta 1965). Seus frutos são numerosos, pequenos, de coloração vermelho-brilhante e portadores de uma secreção pegajosa que exerce um efeito paralisante sobre pássaros, quando ingeridos, provavelmente devido ao efeito tóxico da secreção (Kaistha \& Kier 1962).

Embora o sistema secretor nesta família tenha sido estudado por diversos autores (Fahn \& Evert 1974; Fahn 1979; Joel \& Fahn 1980a; b; c; Nair et al. 1983; Venkaiah 1992; Carmello et al. 1995), os trabalhos referemse, em sua maior parte, aos canais secretores presentes nos órgãos vegetativos, existindo poucas informações sobre os frutos.

O objetivo deste trabalho foi descrever a estrutura e o desenvolvimento do sistema secretor nos frutos de Schinus terebinthifolius.

\section{Material e métodos}

Amostras de botões florais, flores e frutos em diferentes estágios de desenvolvimento, foram coletadas de exemplares de Schinus terebinthifolius crescendo na vegetação natural no município de Botucatu, SP, Brasil (exsicata BOTU 23419).
Para o estudo anatômico, foram utilizadas amostras de material fresco e fixado em solução de Karnovsky (Karnovsky 1965). Do material fresco foram obtidas seções a mão livre e analisadas ao natural. As amostras fixadas foram desidratadas em série etílica e incluídas em glicol-metacrilato (Gerrits

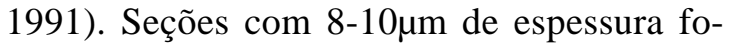
ram coradas com azul de toluidina a $0,05 \%$ em tampão acetato pH 4,7 (O'Brien et al. 1964).

Para o estudo ultra-estrutural, as amostras foram fixadas em glutaraldeído a $2,5 \%$, pósfixadas em tetróxido de ósmio a $1 \%$, ambos preparados em tampão fosfato $0,1 \mathrm{M}, \mathrm{pH} 7,3$, desidratadas em série cetônica e incluídas em Araldite. As seções ultrafinas foram contrastadas com acetato de uranila (Watson 1958) e citrato de chumbo (Reynolds 1963) e examinadas em microscópio eletrônico de transmissão Philips EM-301.

\section{Resultados}

Nos frutos de $S$. terebinthifolius o sistema secretor é representado por inúmeras cavidades que ocupam quase todo o mesocarpo. Essas cavidades variam de circulares a ovaladas, tanto em seções transversais quanto longitudinais e ocorrem associadas ao floema (Fig. 1). Cada cavidade é constituída por lume e epitélio secretor formado por células conspícuas, variando de cuneiformes a esféricas, dispostas em uma ou mais camadas (Fig. 1, 6). As células epiteliais apresentam citoplasma denso e abundante, núcleo esférico e nucléolo evidente (Fig. 7). Circundando cada cavidade ocorrem duas a três camadas de células parenquimáticas achatadas e menores que as epiteliais, com núcleo volumoso, esférico e nucléolo evidente, dispostas regularmente, formando uma bainha com característica meristemática (Fig. 5, 7).

As cavidades se formam precocemente no botão floral e desenvolvem-se nas adjacências 


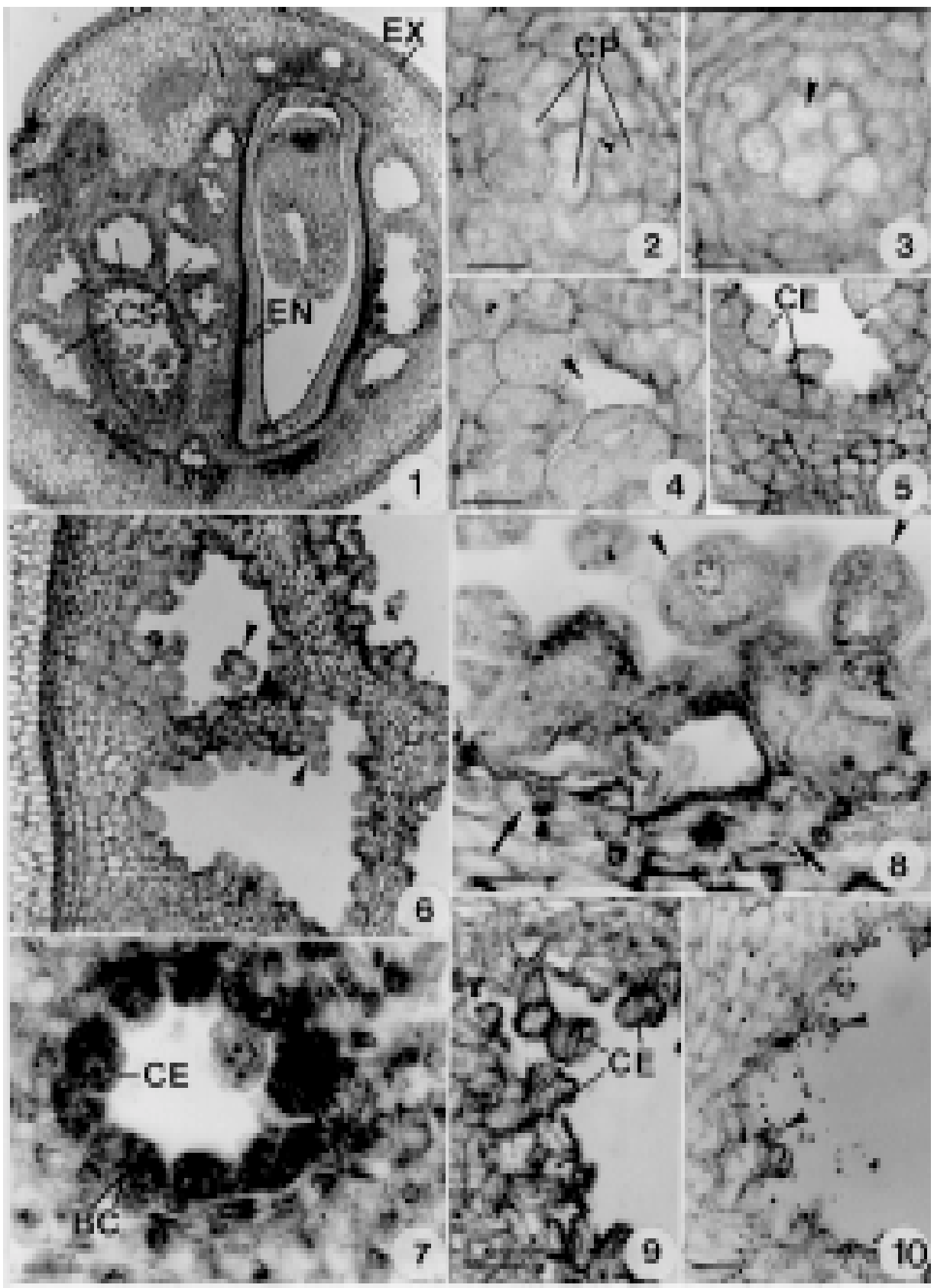

Figuras 1-10. Fotomicrografias de seções de frutos de S. terebinthifolius. Fig. 1. Seção longitudinal do fruto imaturo, mostran do cavidades secretoras (CS) na região mais interna do mesocarpo e exocarpo (EX). Endocarpo (EN). Barra=500 $\mu \mathrm{m}$. Fig. 2 10. Seções transversais. Fig. 2-4. Células precursoras (CP) da cavidade, dispostas em roseta. As pontas de seta indicam a presença de um espaço intercelular no cento da roseta. Barra $=40 \mu \mathrm{m}$. Fig. 5. Parte de uma cavidade secretora com bainha de células com característica meristemática (seta). Células epiteliais (CE). Barra $=40 \mu \mathrm{m}$. Fig. 6. Células epiteliais (pontas de seta) com arranjo laxo ou dispersas no lume da cavidade. Barra=50 $\mu \mathrm{m}$. Fig. 7. Cavidade recém formada.Células epiteliais $(\mathrm{CE})$ protuberantes e bainha celular $(\mathrm{BC})$ bisseriada. Barra $=30 \mu \mathrm{m}$. Fig. 8. Células epiteliais (pontas de seta) em processo de liberação para o lume; células da bainha em divisão (setas). Barra $=10 \mu \mathrm{m}$. Fig. 9. Parte de uma cavidade, mostrando células epiteliais (CE) senescentes. Barra=40 $\mu \mathrm{m}$. Fig. 10. Glóbulos densos (pontas de seta) dispersos no lume e aderidos à superfície de células epiteliais degeneradas. Barra $=40 \mu \mathrm{m}$. 


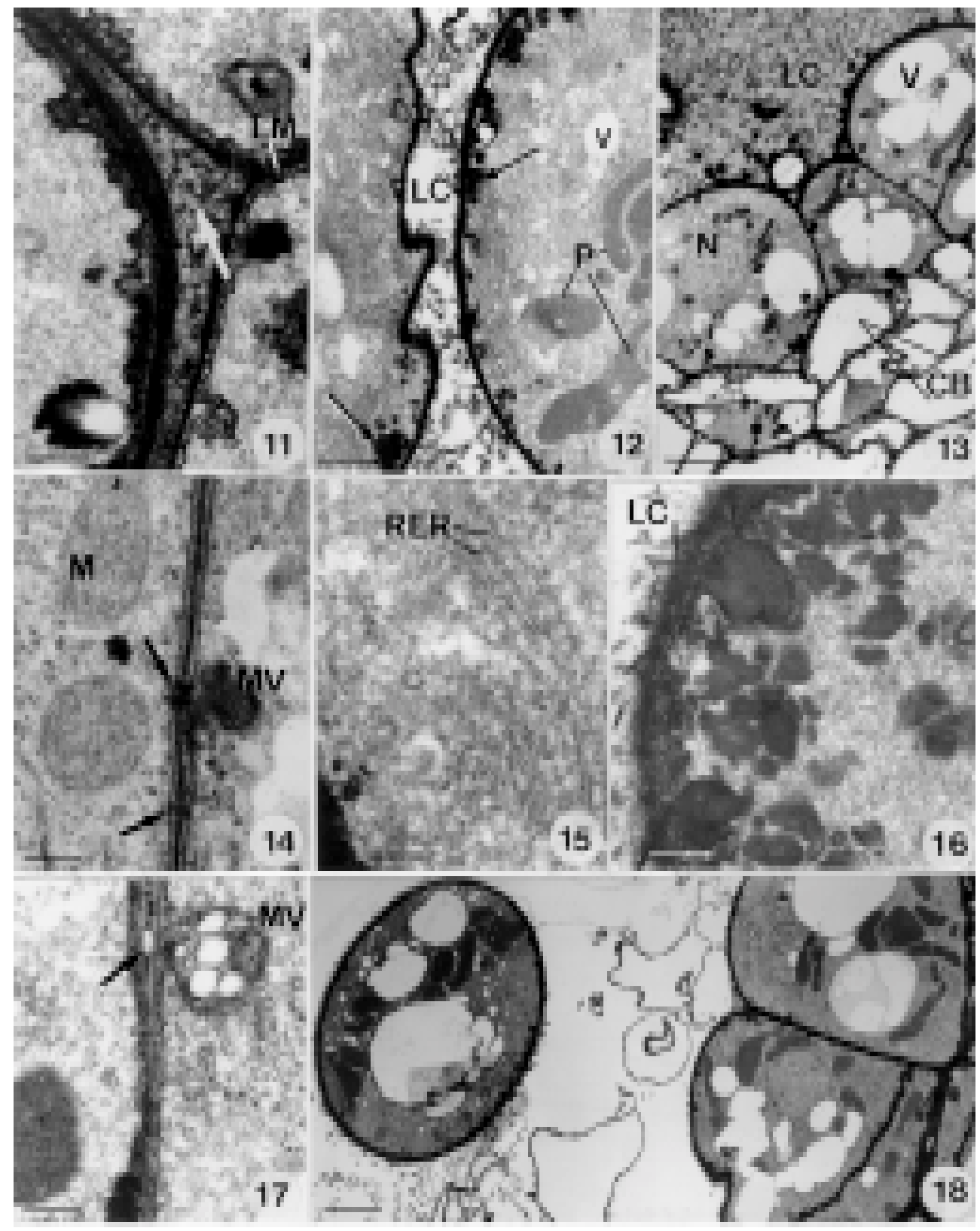

Figuras 11-18. Eletron-micrografias de cavidades secretoras de frutos de S. terebinthifolius. Fig. 11. Formação de espaço triangular (seta) entre células precursoras da cavidade. Paredes celulares eletron-densas e lamela média (LM) intumescida. Barra $=0,3 \mu \mathrm{m}$. Fig. 12. Células precursoras, mostrando plastídeos (P) amebóides e corpos multivesiculares (setas) nas adjacências da parede tangencial. Lume da cavidade (LC) com material eletron-denso disperso. Barra $=1 \mu \mathrm{m}$. Fig. 13. Parte de uma cavidade secretora, mostrando lume (LC) preenchido por secreção de aspecto heterogêneo. Células epiteliais protuberantes com paredes tangenciais convexas, núcleo $(\mathrm{N})$ central esférico, vacúolos $(\mathrm{V})$ e células da bainha $(\mathrm{CB}) \mathrm{em}$ divisão. Barra=3,6 $\mu \mathrm{m}$. Fig. 14. Parte de células epiteliais mostrando mitocôndrias (M), corpos multivesiculares (MV) e plasmodesmos (setas) nas paredes radiais. Barra $=0,3 \mu \mathrm{m}$. Fig. 15. Parte do citoplasma de célula epitelial, mostrando retículo endoplasmático rugoso (RER). Barra=0,4 $\mu \mathrm{m}$. Fig. 16. Acúmulos de material eletron-denso no citoplasma periférico da célula epitelial. Lume da cavidade (LC). Barra=0,4 $\mu \mathrm{m}$. Fig. 17. Início de separação de paredes radiais (seta) e corpo multivesicular (MV) adjacente à parede. Barra $=0,4 \mu \mathrm{m}$. Fig. 18. Parte de cavidade secretora mostrando célula epitelial e restos celulares dispersos no lume. Barra $=0,3 \mu \mathrm{m}$. 
do procâmbio do mesofilo ovariano. As células precursoras da cavidade sofrem sucessivas divisões, originando grupos de células dispostas em roseta (Fig. 2). No centro da roseta, ocorre a formação de um pequeno espaço intercelular triangular iniciando-se assim, o lume (Fig. 2, 3, 4, 11); as células centrais sofrem um pronunciado aumento de tamanho (Fig. 2, 4), seguido do escurecimento, intumescimento e dissolução da lamela média (Fig. 4, 11). A ampliação do lume é o resultado da separação de uma ou mais células internas desta roseta (Fig. 3-5). Simultaneamente à diferenciação das células precursoras, as células da bainha subjacente sofrem constantes divisões nos planos periclinal e anticlinal e suas derivadas diferenciam-se, passando a integrar o epitélio secretor (Fig. 5, 7, 8), cuja diferenciação se dá centripetamente em direção ao lume.

À medida que ocorre formação e diferenciação de novas células epiteliais, há progressiva liberação das células epiteliais mais internas para o lume. Esta liberação é resultante da dissolução da lamela média em toda a extensão da célula (Fig. 5-8). Em seções tanto de material fresco quanto fixado as células epiteliais mais internas mostram arranjo laxo (Fig. 8, 9), podendo ser observadas células inteiramente livres no lume sem qualquer conexão umas com as outras (Fig. 6, 18). As células epiteliais senescentes mostram paredes sinuosas, glóbulos densos no citoplasma e núcleo lobado com cromatina granulada (Fig. 8). Finalmente, estas células entram em colapso e liberam o conteúdo no lume da cavidade (Fig. 10).

As células epiteliais jovens apresentam espaço periplasmático conspícuo com acúmulos de material fortemente eletron-denso (Fig. 11), citoplasma abundante com ribossomos livres (Fig. 11-15), mitocôndrias (Fig. 14), retículo endoplasmático rugoso (Fig. 15), plastídeos amebóides (Fig. 12, 13, 18) e numerosos corpos multivesiculares (Fig. 12, 14,
17). Os corpos multivesiculares são fortemente eletron-densos e situam-se nas adjacências das paredes celulares, preferencialmente nas proximidades dos plasmodesmos (Fig. 14, 17). Estes se tornam progressivamente obstruídos por substâncias eletron-densas (Fig. 14). Acúmulos de material eletron-denso, destituídos de membrana limitante, ocorrem no pólo distal da célula epitelial, dispersos no citoplasma periférico, no interior do espaço periplasmático e na superfície externa da parede que faceia o lume (Fig. 13, 16).

\section{Discussão}

As análises estruturais mostraram que as cavidades secretoras no pericarpo de $S$. terebinthifolius iniciam-se por esquizogênese e sua ampliação é decorrente da formação e liberação, também por esquizogênese, de células epiteliais mais internas para o lume da cavidade. A lisogênese posterior dessas células epiteliais contribui com materiais para a secreção e permite, também, a ampliação da cavidade.

Processos esquizógeno, lisígeno e esquizolisígeno de formação do lume de canais secretores são comuns em Anacardiaceae (McNair 1918; Harada 1937; Venning 1948; Paula \& Alves 1973; Carmello et al. 1995), sendo que, em diferentes órgãos de uma mesma espécie, os canais podem desenvolver-se de diferentes maneiras (Venning 1948).

Esquizogênese acompanhada da liberação das células epiteliais mais internas para o lume da cavidade, onde sofrem lise, como verificado no presente trabalho, é um padrão que foi descrito uma única vez na família por Bhatt \& Mohan Ram (1992) em Semecarpus anacardium. Padrão semelhante já havia sido observado por Mauseth (1980) em canais secretores de mucilagem de duas espécies de Nopalea (Cactaceae) e por Wittler \& Mauseth (1984b) em ductos laticíferos de Mammilaria guerreronis (Cactaceae). Mauseth (1980) re- 
fere a ocorrência de cavidades secretoras em frutos de Pereskia pilitache onde células ou grupos de células vivas flutuam livremente no lume da cavidade. Segundo este mesmo autor, a liberação de células íntegras, isoladas ou agrupadas, para o lume de sistemas secretores é pouco comum e seu significado é desconhecido.

É importante ressaltar que células livres no lume da cavidade secretora dos frutos de $S$. terebinthifolius foram observadas tanto em cortes de material fresco quanto de material fixado, em Karnovsky ou em glutaraldeído e tetróxido de ósmio, reduzindo, assim, a possibilidade de representarem um artefato de técnica, conforme observações de Turner et al. (1998).

As características ultra-estruturais mais marcantes das células epiteliais, desde o início da diferenciação da cavidade secretora, incluem a ocorrência de corpos multivesiculares, plastídeos amebóides e acúmulos de material eletron-denso no protoplasto, no espaço periplasmático e na superfície externa das paredes que faceiam o lume. Características similares foram descritas para canais secretores de goma-resina de outras Anacardiaceae (Joel \& Fahn 1980 a; b; c; Nair et al. 1983; Venkaiah 1992; Carmello et al. 1995). A abundância de corpos multivesiculares no citoplasma periférico das células epiteliais pode estar relacionada com processos de dissolução da lamela média, uma vez que estas estruturas participam da síntese e eliminação de enzimas líticas (Hall et al. 1984).

Algumas evidências como presença de grumos de material eletron-denso dispersos no citoplasma periférico e no espaço periplasmático, e a ocorrência de lisogênese de células epiteliais livres no lume sugerem que a eliminação da secreção nos frutos de $S$. terebinthifolius ocorre por mecanismos écrino e holócrino, respectivamente (Fahn 1979).
A presença de uma bainha multiestratificada ao redor da cavidade secretora, produzindo novas células epiteliais, possibilita a renovação de células e a manutenção da atividade secretora durante o desenvolvimento dos frutos de $S$. terebinthifolius. A formação e diferenciação de novas células epiteliais, a partir da bainha celular subjacente à cavidade, formando um epitélio multisseriado, já foi verificado em espécies de Asteraceae como Tagetes minuta (Fueyo 1986) e Porophyllum lanceolatum (Monteiro et al. 1994).

Este padrão de desenvolvimento aberto, onde células do tecido fundamental mantêm o potencial para diferenciação em células epiteliais, sem uma aparente desdiferenciação, foi igualmente observado em ductos laticíferos de Mammilaria heyderi por Wittler \& Mauseth (1984a).

\section{Agradecimentos}

À equipe técnica do Centro de Microscopia Eletrônica do Instituto de Biociências, UNESP, Câmpus de Botucatu, pelo auxílio no preparo das amostras.

\section{Referências bibliográficas}

Barroso, G. M.; Guimarães, E. F.; Ichaso, C. L. F.; Costa, C. G. \& Peixoto, A. L. 1984. Sistemática de angiospermas do Brasil. v.2. Editora UFV, Viçosa.

Bhatt, J. R. \& Mohan Ray, H. Y. 1992. Development and ultrastructure of primary secretory ducts in the stem of Semecarpus anacardium (Anacardiaceae). IAWA Bull. n.s. 13(2): 173-185.

Carmello, S. M.; Machado, S. R. \& Gregório, E. A. 1995. Ultrastructural aspects of the secretory duct development in Lithraea molleoides (Vell.) Engl. (Anacardiaceae). Revista Brasileira de Botânica 18(2): 95-103.

Carmello-Guerreiro, S. M. 1996. Morfologia, anatomia e desenvolvimento dos frutos, sementes e plântulas de Schinus terebinthifolius Raddi, Lithraea molleoides (Vell.) Engl., Myracrodruon urundeuva Fr. Allem. e Astronium graveolens Jacq. (Anacardiaceae). Tese de Doutorado, Universidade Estadual Paulista, Rio Claro. 
Carmello-Guerreiro, S. M. \& Paoli, A. A. S. 1999. Morfologia e anatomia da semente de Schinus terebinthifolius Raddi (Anacardiaceae) em desenvolvimento. Revista Brasileira de Botânica 22(1): 91-98.

Fahn, A. \& Evert, R. F. 1974. Ultrastructure of secretory ducts of Rhus glabra L. American Journal of Botany 61: 1-14.

Fahn, A. 1979. Secretory tissues in plants. Academic Press, London.

Fueyo, G. M. 1986. Ontogenia de las glándulas foliares y involucrales de Tagetes minuta (Compositae). Boletín de la Sociedad Argentina de Botánica 24: 403-410.

Gerrits, P. O. 1991. The application of glycol methacrylate in histotechnology; some fundamental principles. Department of Anatomy and Embryology State University Groningen, Netherlands.

Hall, J. L.; Flowers, T. J. \& Roberts, R. M. 1984. Plant cell structure and metabolism. Longman, New York.

Harada, M. 1937. On the distribution and construction of resin canal in Rhus succedanea. Botanical Magazine 51: 846-856.

Joel, D. M. \& Fahn, A. 1980a. Ultrastructure of resin ducts of Mangifera indica L. (Anacardiaceae). I. Diferentiation and senescence of the shoot ducts. Annals of Botany 46(2): 225-23.

Joel, D. M. \& Fahn, A. 1980b. Ultrastructure of resin ducts of Mangifera indica L. (Anacardiaceae). II. Resin secretion in the primary stem ducts. Annals of Botany 46(6): 779-783.

Joel, D. M. \& Fahn, A. 1980c. Ultrastructure of resin ducts of Mangifera indica L. (Anacardiaceae). III. Secretion of protein-polysaccharide mucilage in fruit. Annals of Botany 46(6): 785-790.

Kaistha, K. K. \& Kier, L. B. 1962. Structural studies on terebinthone from Schinus terebinthifolius. Journal of Pharmaceutical Sciences 51: 245 248.

Karnovsky, M. J. 1965. A formaldehydeglutaraldehyde fixative of high osmolality for use in electron microscopy. Journal of Cell Biology 27: 137A-138A.

Mauseth, J. D. 1980. Release of whole cells of Nopalea (Cactaceae) into secretory canals. Botanical Gazette 14(1): 15-18.

Metcalfe, C. R. \& Chalk, L. 1950. Anatomy of dicotyledons. v.1. Claredon Press, Oxford.

McNair, J. 1918. Secretory canals of Rhus diversiloba.
Botanical Gazette 65: $268-273$.

Monteiro, W. R., Castro, M. M., Fahn, A. \& Caldeira, W. 1994. Observations on the development of the foliar secretory cavities of Porophyllum lanceolatum (Asteraceae). Nordic Journal of Botany 15(1): 69-76.

Nair, G. M., Venkaiah, K. \& Shah, J. J. 1983. Ultrastructure of gum-resin ducts in cashew (Anacardium occidentale). Annals of Botany 51 : 297-305.

O’Brien, T. P., Feder, N. \& McCully, M. E. 1964. Polychromatic staining of plant cell walls by toluidine blue O. Protoplasma 59: 368-373.

Oliveira, F. \& Grotta, A. S. 1965. Contribuição ao estudo morfológico e anatômico de Schinus terebinthifolius Raddi (Anacardiaceae). Revista da Faculdade de Farmácia e Bioquímica da Universidade de São Paulo 3: 271-93.

Paula, J. E. \& Alves, J. L. H. 1973. Anatomy of Anacardium spruceanum Bth. ex. Engl. (Anacardiaceae) of Amazonia. Acta Amazonica 3: $39-52$.

Reynolds, E. S. 1963. The use of the lead citrate at high $\mathrm{pH}$ as an electron-opaque stain in electron microscopy. Journal of Cell Biology 17: 208.

Turner. G. W., Berry, A. M. \& Gifford, E. M. 1998. Schizogenous secretory cavities of Citrus limon (L.) Burm. F. and a reevaluation of the lysigenous gland concept. International Journal of Plant Sciences 159(1): 75-88.

Venkaiah, K. 1992. Develoment, ultrastructure and secretion gum ducts in Lannea coromandelica (Houtt) Merrill (Anacardiaceae). Annals of Botany 69: 449-457.

Venning, F. D. 1948. The ontogeny of the laticiferous canals in the Anacardiaceae. American Journal of Botany 35: 637-644.

Watson, M. L. 1958. Staining of tissue sections for electron microscopy with heavy metals. Journal of Biophysics and Biochemistry Citology 4: 475.

Wittler, G. H. \& Mauseth, J. D. 1984a. The ultrastructure of developing latex ducts in Mammilaria heyderi (Cactaceae). American Journal of Botany 71(1): 100-110.

Wittler, G. H. \& Mauseth, J. D. 1984b. Schizogeny and ultrastructure of developing latex ducts in Mammilaria guerreronis (Cactaceae). American Journal of Botany 71(8): 1128-1138. 